\title{
Chianelli, Hubler, and Olson Chair 1987 MRS Spring Meeting
}

\author{
12 Symposia, Equipment Exhibit, Placement Center Planned
}

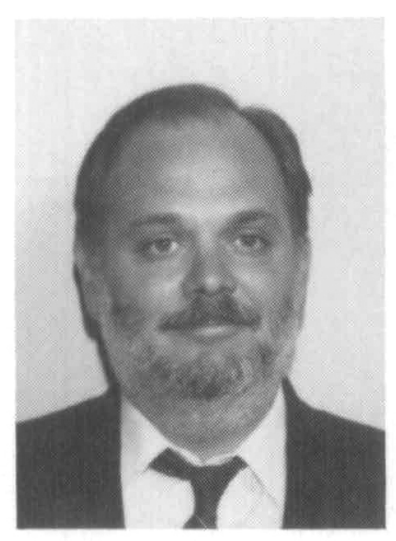

R. R. Chianelli

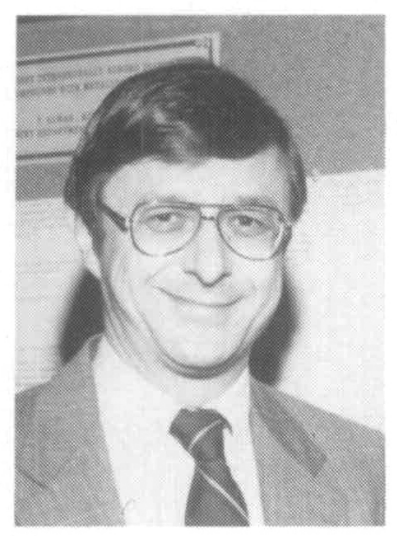

G. K. Hubler

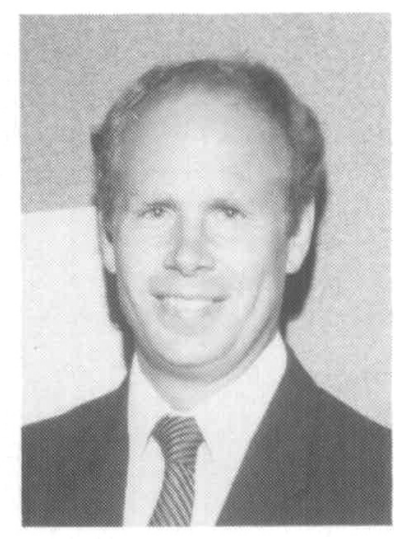

G. L. Olson
Three active MRS members have been appointed Meeting Chairs for the 1987 MRS Spring Meeting to be held in Anaheim, CA, April 21-25, 1987. R. R. Chianelli, G. K. Hubler, and G. L. Olson will direct the logistics and technical emphasis for this meeting, which will include 12 technical symposia, the first MRS West Coast equipment exhibit, an extensive short course program, and a job placement center.

Russ Chianelli received his $\mathrm{PhD}$ in chemistry from the Polytechnic Institute of Brooklyn in 1974, where his interests spanned solid-state chemistry, $x$-ray diffraction, and polymer science. Since 1974 he has been employed by the Corporate Research Laboratories of Exxon Research and Engineering $\mathrm{Co}$., Clinton, $\mathrm{N}$, where he is senior research associate and head of the Catalytic Materials and Chemistry Group. His group, which is interdisciplinary in make-up, works in the areas of solid-state chemistry and physics, materials science, surface science, $x$-ray scattering, organic chemistry, and catalysis. He is the author of over 60 publications and 25 patents in the fields of catalysis, solid-state chemistry, organic and inorganic materials, and electrochemistry.

Chianelli served as co-chair of the symposium on Catalysis by Solids: Bulk Properties, Surface Properties, and Defects at the 1984 MRS Fall Meeting and brings a wealth of experience to his role as Meeting Chair. He sees the 1987 Spring Meeting as an opportunity to include new areas of interdisciplinary materials research which are of current high interest but not traditionally included within previous MRS meetings. "We hope that the ' 87 Spring Meeting will help to create new synergisms with the research community," he said.

Graham Hubler received his PhD in nuclear physics from Rutgers University in 1972 and held a postdoctoral fellow position at the Naval Research Laboratory. He joined NRL in 1975 as staff research physicist in the Radiation Effects Branch. In 1976 he moved to the Materials Modification and Analysis Branch, where he is presently head of the Surface Modification Physics Section. His research interests lie in the field of ion-solid interactions centering on ion beam modification of metals and semiconductors.

Since co-chairing the symposium on Ion Implantation and lon Beam Processing of Materials at the I983 MRS Fall Meeting, Hubler has seen the rapid growth in materials coverage at MRS meetings. His goal for the 1987 Spring Meeting is to offer integrated symposia on emerging topics of interest to West Coast industries and universities and to highlight some new areas that haven't yet been addressed by the Society. "I also want to keep a small posture for the meeting," he said, "so that the problem of overlapping topics of interest can be minimized, and because I believe smaller meetings can produce better informational exchange."

Greg Olson received a BS in chemistry from North Dakota State University in 1972 and $\mathrm{PhD}$ in physical chemistry from the University of Colorado in 1977. His thesis explored picosecond photodynamics in condensed phase systems. He joined Hughes Research Laboratories, where he is currently head of the Laser Chemistry and Processing Section in the Chemical Physics Department. He is involved in $R \& D$ in laser-solid interactions, kinetics and mechanisms of rapid phase transformation in solids, laser-assisted chemistry at semiconductor surfaces, and laser processing of electronic materials.

He has, served on the MRS Corporate Participation Committee and was co-chair of the symposium on Beam-Solid Interactions and Phase Transformations conducted at the 1985 MRS Fall Meeting. He emphasized that the meeting chairs are working to make the 1987 Spring Meeting a valuable in terdisciplinary forum in which new developments in both traditional MRS topical areas and new frontiers can be explored. "The symposium organizers, MRS officers and staff, and The Complete Conference are working closely together to ensure that the topical focus, informal atmosphere and timetable will enable attendees to maximize their week in Anaheim," he said.

\section{Further Information}

See upcoming issues of the BULLETIN for further information on the symposia, exhibit, short courses, and special speakers and events planned for the 1987 Spring Meeting.

MRS

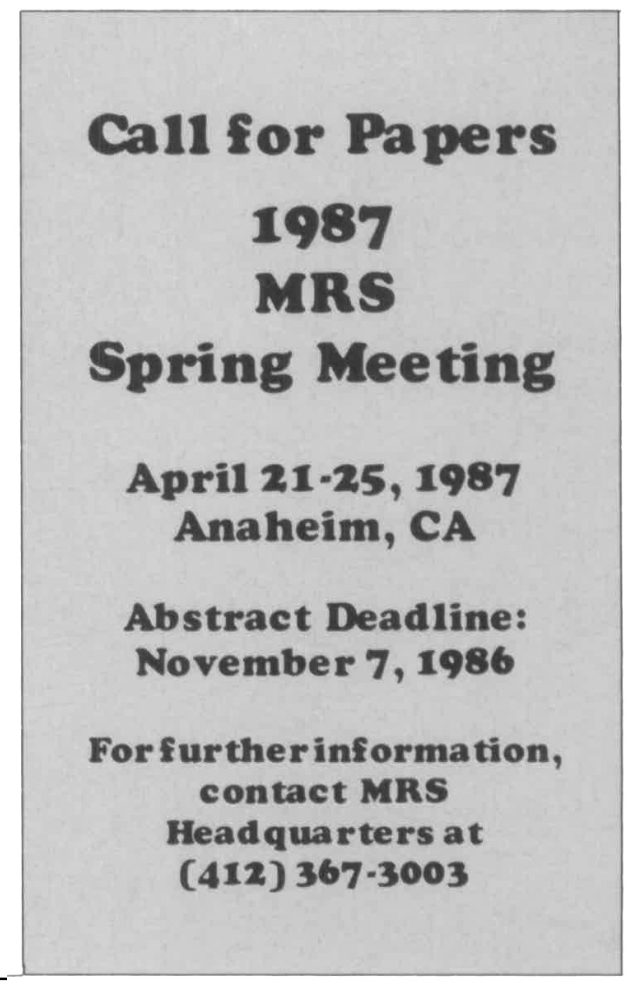

